\title{
De precursor a grande ocultador: Nietzsche sobre Spinoza*
}

\author{
Saulo Krieger**
}

Resumo: Para além da triangulação Nietzsche-Kuno FischerSpinoza, a proposta do texto é perscrutar as peculiaridades da relação entre Nietzsche e Spinoza, partindo não de uma conexão biunívoca e restrita a Nietzsche e Spinoza, mas de menções compartilhadas, em que outros filósofos e pensadores são mencionados. A partir daí se pretende evidenciar traços de uma relação que é de admiração pelo "profundo ocultador", mas também de crítica pelas instâncias que tal ocultador mascarou e que acabaram por consumi-lo.

Palavras-chave: Spinoza, conhecimento, vivência, afetos, vontade de potência.

\footnotetext{
* Este artigo é parte do capítulo I da tese $O$ cerne oculto do projeto nietzschiano: logos versus pathos no ato de filosofar, defendida no Departamento de Filosofia da Escola de Filosofia, Letras e Ciências Humanas da Universidade Federal de São Paulo (Unifesp) em abril de 2019.

** Universidade Estadual do Centro-Oeste (UNICENTRO), Guarapuava, Paraná, Brasil. ORCID https://orcid.org/0000-0003-0251-645X

Correio eletrônico: saulokrieger@hotmail.com
} 
Krieger, S.

\section{Introdução}

Já muito se sabe e se propôs sobre a relação entre Nietzsche e Spinoza. Por exemplo, que compartilharam, por algum tempo, algo da ordem do incomunicável, de vivências singulares, gestadas na solidão, jamais partilhadas. ${ }^{1}$ Mas a pesquisa Nietzsche já fez ver, com muita acuidade, que Nietzsche não leu Spinoza diretamente, e sim pela via de Kuno Fischer e de outras fontes, como talvez Adolf Trendelemburg e Richard Falckenberg. ${ }^{2}$ A sua leitura indireta, porém, como já ficou claro, de modo algum pode ser tida como um comentário superficial. ${ }^{3}$ Sabe-se que essa mesma leitura, pela obra de Kuno Fischer, Geschichte der Neuern Philosophie, estaria sujeita às diferenças de uma para outra edição dessa obra. ${ }^{4} \mathrm{E}$ brilhantemente já se mostrou que Nietzsche teria se valido de Spinoza para dali haurir benefícios para o seu próprio filosofar, como nas questões da negação da teleologia, da negligência ao conatus como aumento de potência e da secularização do amor intellectualis dei no amor fati. ${ }^{5}$ É verdade, ademais, que após a eulogia inicial a Spinoza, em carta de 1881, Nietzsche teria mais e mais procurado enaltecer as diferenças entre ele e o filósofo holandês, como também aqui se verá. A pesquisa Nietzsche, como se depreende, já apontou para algumas direções, já se perguntou e se respondeu - provisoriamente, o debate

1 Cf. S. Marton, 2010, p. 49 e 63.

2 Cf. M. Scandella, 2012. A esse respeito, Andreas Urs Somme, faz reiteradas menções a "Fischer's Spinoza" e assemelhados, em referência ao Spinoza com que Nietzsche efetivamente travou contato (Andreas Urs Somme, 2012, p. 165). Antes disso, Thomas Brobjer (2008, p. 77) já afirmara, de forma peremptória, "Nietzsche jamais leu Spinoza".

3 G. B. Costa, 2017, em especial p. 9. Entretanto, a esse respeito já se considerou simplesmente irrelevante "discutir as interpretações e equívocos de Nietzsche com relação aos próprios escritos de Spinoza" [em livre tradução] (cf. Brobjer, 2012, p. 77). Ocorre que não se está pretendendo aqui trazer Nietzsche como historiador da filosofia, e sim compreender a própria filosofia de Nietzsche à luz de seus comentários a outros filósofos, à luz da sua visão muito peculiar dos pontos cegos (inconscientes) na história da filosofia.

4 Cf. Scandella, 2012, p. 309 e p. 315.

5 Cf. Sommer, 2012, p. 156-185, em especial p. 168, 175 e 178.

232 | Cad. Nietzsche, Guarulhos/Porto Seguro, v.42, n.1, p. 231-251, janeiro/abril, 2021. 
está aberto, mas bem encaminhado - sobre uma série de questões a envolver a relação de Nietzsche com Spinoza.

Sabemos já se tratar de um Nietzsche crítico de Spinoza e ao mesmo tempo aparentado a ele, e que o trágico pode estar afinado ao conhecimento do terceiro tipo, em Spinoza; ${ }^{6}$ sabemos de um Nietzsche que ocultaria o desejo de tirar proveito de Spinoza sob o biombo de suas críticas ao filósofo judeu. ${ }^{7} \mathrm{Um}$ Nietzsche sobre Spinoza basicamente triangulado por Kuno Fischer, como aliás foi, no geral, boa parte da visão de Nietzsche sobre outros filósofos modernos. ${ }^{8}$ Aliás, e bem entendido, a pesquisa Nietzsche está habituada a pensar a visão do filósofo sobre Spinoza sempre a partir do "binômio" Nietzsche $e$ Spinoza, sem mais. Mas as maneiras de intentar compreender a relação entre um e outro se reduziriam à tal biunivocidade? De nossa parte, acreditamos que não. $\mathrm{O}$ que propomos é um ligeiro deslocamento de ponto de partida, uma abordagem que, imanente, não se valha só da relação Nietzsche e Spinoza por uma via direta, mas sobre se e em que medida a relação do primeiro com o segundo não evidenciaria algo de sua peculiaridade justamente ao se tentar subsumi-la a uma "não peculiaridade", a saber: ao denominador comum da relação de Nietzsche com a tradição, com outros filósofos e pensadores. A partir daí, no entanto, pretende-se chegar não à relação com todos os demais, mas a uma peculiaridade da relação entre Nietzsche e Spinoza, e entenda-se, chegar no ponto em que precisamente incidiria a crítica do filósofo alemão ao seu

6 Cf. A. Martins, 2000.

7 Cf. Sommer, 2012, p. 168.

8 Nietzsche poderia estar até mesmo, em dado momento, ocultando o seu contato com Spinoza pela via exclusiva de Kuno Fischer, ou então indo além da compreensão de Kuno Fischer sobre Spinoza, mesmo sendo esta talvez a principal (ou única) fonte a respeito. Na Genealogia da moral, o filósofo comenta: "De maneira insidiosa isto [a má consciência] ocorreu certa vez a Spinoza (para desgosto de seus intérpretes, que se esforçam devidamente para não compreendê-lo nisso, Kuno Fischer, por exemplo)" (GM/GM, II, 15, KSA 5.320). 
Krieger, S.

"precursor", que, de resto, lhe seria alvo de uma admiração entre manifesta e ocultada.

\section{Spinoza ocultador nas profundezas}

Analisando as referências de Nietzsche a Spinoza que se mostram extensivas à tradição que vai de Descartes a Schopenhauer, eventualmente remontando a Giordano Bruno, passando por Pascal e pelos louvores a Goethe, três noções evidenciam-se pela magnitude e pela reincidência: a de ocultação e a de disfarce, entre si entremeadas, e a de viver o que se filosofa. As primeiras são invocadas mesmo em relação aos antigos: mesmo os gregos teriam ocultado o seu afeto agonal, "edulcorando-se" como "os mais felizes" (cf. Nachlass/FP 1884, 26 [285], KSA 11.226). Giordano Bruno e Spinoza, de tanto ocultar, "sob a máscara mais espiritual", tornaram-se eremitas, e, com isso, "em refinados rancorosos e envenenadores" (JGB/BM 25, KSA 5.43). Idealistas como Platão e Spinoza dissimularam sua cautela em relação à saúde e sua dessensualização com sedutoras ideias idealistas (FW/GC 372, KSA 3.624). Em menções compartilhadas Spinoza e Kant, Schopenhauer e Leibniz, Pascal, Goethe, Descartes, Rousseau... -, o esquadrinhamento seria: Spinoza até certo ponto viveu o seu filosofar, ao contrário dos alemães, absorvidos pela sua segunda natureza, alemã (cf. Nachlass/FP 1884, 26 [285], KSA 11.226) - os alemães e sua não vivência são bem um capítulo à parte,$-{ }^{9}$ o holandês teria dado vazão a propriamente uma alma não apenas a um espírito ou a um caráter -, mas muito teria, sim, ocultado. Menções neutras deixam entrever o seu disfarce: o "gênio do saber", "o mais puro dos sábios" (MM/HH 157, KSA 2.157-148 e 475, KSA 2.309). Mas as menções compartilhadas têm o dom de nos revelar uma adicional chave de compreensão: além da ocultação, a profundidade do que se ocultou - "Spinoza é um ocultador de

9 Cf. S. Krieger 2019, em especial p. 35-42 e J. Viesenteiner, 2013.

234 | Cad. Nietzsche, Guarulhos/Porto Seguro, v.42, n.1, p. 231-251, janeiro/abril, 2021. 
cavernas mais profundo do que Descartes" (Nachlass/FP, 188536 [32], KSA 11.563).

Em comum, assim, com o também seiscentista e antecessor Descartes, Spinoza guarda igualmente a dissimulação: ambos imaginam e dissimulam suas obras, pensam que a realidade é feia -e não acham que o conhecimento a pode embelezar -, fazem as vezes de panegiristas das coisas e de fruidores do próprio conhecimento (cf. M/A 550, KSA 3.320-321). Compartilham também do desprezo em relação a tudo o quanto se move (cf. Nachlass/FP 1887, 9 [160], KSA 12.430), a ingenuidade em um e outro estando em valorizar o que eternamente se mantém igual a si (Ewig-Gleichbleibende) (cf. Nachlass/FP 1887, 9 [26], KSA 12.348). E em relação a ambos, Nietzsche fala mesmo de "equívocos de ordem psicológica", extensíveis a Schopenhauer e Kant, que tornam suas filosofias regadas a "experiências psicológicas mal interpretadas" (Nachlass/FP 1886-1887, 7 [4], KSA 12.262263), como se houvesse a incidência num ponto cego. Porém esse equívoco se manifestaria de diferentes maneiras. ${ }^{10}$ Nas referências críticas de Nietzsche a Spinoza, ao contrário do que se tem com o quase contemporâneo menos profundo, Descartes (cf. Nachlass/FP 1885, 40 [20], KSA 11.637), a questão da crença na linguagem não está presente. Afinal de contas, de certo modo como em Nietzsche, na filosofia de Spinoza a linguagem tem uma codificação própria, e isto significa, tem uma autonomia interna a diferenciá-la da linguagem e da terminologia de qualquer outra doutrina, e essa autonomia em ampla medida a distingue do uso corrente e irrefletido ${ }^{11}$ - a começar pela própria noção de Deus, com que o filósofo holandês inicia a sua obra capital. Imanente e identificado à natureza - com isso a suscitar a adesão de Nietzsche -, seu Deus de modo algum tem a conotação da divindade judaica ou cristã - punitiva, num caso, amorosa e providencial em outro. Essa reinterpretação configura um

10 Sobre o modo como se deu com Descartes, cf. S. Krieger, 2018.

11 Cf. S. Krieger, 2018, p. 236.

Cad. Nietzsche, Guarulhos/Porto Seguro, v.42, n.1, p. 231-251, janeiro/abril, 2021. | 235 
Krieger, S.

processo que se pode caracterizar como, quase a antecipar Nietzsche, de ressignificação de um conceito, de deslocamento do sentido de um termo corrente - e se é corrente é imerso em automatismo e irreflexão. É muito possível que, por sua proveniência, sendo oriundo de um meio judeu ortodoxo numa Europa majoritariamente cristã, Spinoza tenha aprendido a olhar o mundo de maneira oblíqua, com a consciência de suas próprias lentes e da posição em que se encontrava: se era crítico, como crítico é todo filósofo, era crítico oriundo de um bolsão minoritário, ou seja, duplamente crítico. Pois aos 24 anos, em 1656, foi excomungado de seu próprio ambiente judeu, e logo virá a ser, de um modo ou de outro, rejeitado por todas as comunidades religiosas, como será anatemizado por toda a Europa no século seguinte. ${ }^{12}$ Spinoza, desse modo, era um caso especialmente sensível num mundo e num tempo em que razões religiosas, que aliás se revestiam de força política, exerciam franco poder intimidatório. A condenação de Giordano Bruno à fogueira em 1600 é aqui o exemplo mais eloquente. Por tudo isso, em Spinoza reflexão e cautela sobre o uso da linguagem revelam-se algo de muito mais intenso do que em Descartes, cuja cautela passava por abster-se de propor o mundo infinito, preferindo-o "indefinidamente extenso", e por abster-se de se pronunciar sobre questões políticas. Mas quanto a Spinoza, foi com uma desconfiança balizada e fundamentada que se acercou da letra que era bem a mais inquestionada e reverenciada: as Escrituras. Pelo seu método hermenêutico, a leitura da Bíblia deveria seguir os mesmos princípios do método usado para o estudo da natureza, e isto significa, seria necessário se valer de um conhecimento histórico preciso para então desvelar o pensamento de seus autores, assim como para se interpretar a natureza seria preciso construir uma história natural. ${ }^{13}$ Desse modo, ele se pôs a refletir sobre condições,

12 Caso emblemático desse anátema foi a "questão Spinoza", Spinoza-Streit, a envolver Theodor E. Lessing e Moses Mendelssohn. A esse respeito, cf. T. Yasukata, 2002.

13 B. Espinosa, 2003, p. 119.

236 | Cad. Nietzsche, Guarulhos/Porto Seguro, v.42, n.1, p. 231-251, janeiro/abril, 2021. 
circunstâncias históricas e, com base nelas, sobre o texto que dali se produziu - algo muito diferente da atitude de simplesmente partir de palavras e nelas confiar às cegas. Pelo seu uso escrupuloso e refletido da linguagem, e à luz contrastante do que se tem com o "superficial" Descartes (cf. Nachlass/FP 1885, 40 [10], [20], KSA 11.632 e JGB/ BM § 191, KSA 4.113), é possível depreender que Spinoza já não se faria tão exposto a algo como, por exemplo, intromissões inconscientes no uso linguístico, à pressa de se agarrar a um "penso, logo, existo". ${ }^{14}$ Se nuançado é Spinoza em relação a Descartes, ocultador a ocultar em nível mais profundo que o da linguagem corrente, nuançada e profunda há de ser a reação que ele suscita em Nietzsche, como acima anunciávamos, se se levar em conta que há afinidades um dia reveladas por Nietzsche em relação ao autor da Ética - nunca de todo abandonadas, ao que muita coisa indica. ${ }^{15} \mathrm{Em}$ primeiro lugar, tem-se notadamente a já célebre e incontornável carta a Franz Overbeck de 30 de julho de 1881, na qual o filósofo declara ser Spinoza seu precursor, afirma coincidir com ele quanto à sua "tendência geral" e com ele "se reencontrar" em nada menos do que cinco pontos principais de sua teoria. ${ }^{16}$ No mesmo período se tem que Spinoza é também um dos pensadores cujo sangue lhe corre nas veias, estando em companhia de Platão, Pascal e Goethe (cf. Nachlass/FP 1881, 12 [52], KSA 9.585). E é elogiosamente referido por Nietzsche como "aristocrata" (Nachlass/FP 1881, 15 [17], KSA 9.642), ${ }^{17}$ classificação

14 Cf. S. Krieger, 2018.

15 Cf. nota 6.

16 A "tendência global" é a de fazer do conhecimento o afeto mais poderoso, e os cinco pontos capitais são "ele [Spinoza] nega a existência da liberdade da vontade, de fins, da ordem moral do mundo, do não egoísmo, do Mal", e acrescenta que "se por certo que nossas divergências são igualmente imensas, pelo menos elas repousam mais sobre as condições diferentes de cada época, da cultura, dos saberes" (carta a Franz Overbeck, 30 jul. 1881).

17 “Quanto ao que movia Zaratustra, Moisés, Maomé, Jesus, Platão, Brutus, Spinoza, Mirabeau, também eu o vivo, em uma série de coisas me aparece, amadurecido, à luz do dia, o que, como embrião, demandou alguns milhares de anos. Nós somos os primeiros aristocratas da história do espírito - o sentido histórico inicia-se tão-somente agora" (15 [17], outono de 1881 KSA 9.642). 
Krieger, S.

esta que, diga-se, não remete a uma pureza de sangue no tocante a linhagem ancestral, e sim a uma pureza de valores, verticalizada no âmbito de uma mesma singularidade pulsional. ${ }^{18}$

\section{Spinoza, filósofo da hipocrisia profunda}

Qualquer que tenha sido a intenção de Nietzsche, acobertar o intento de "valer-se de", afetar originalidade a toda prova, ${ }^{19}$ ou um genuíno fastio, a lua de mel fraterna com Spinoza parece não ter durado muito, ou ao menos parece ter assumido um ponto de inflexão, ${ }^{20}$ e com um breve passar de tempo as alardeadas proximidades, afinidades, consanguinidades - sempre entremeados a menções neutro-elogiosas (como em MM/HH 157 e 475, KSA 2.147-148 e KSA 2.310) - não impediram que Nietzsche arrolasse Spinoza entre os filósofos "da hipocrisia". A hipocrisia em questão estaria numa esfera justa e especialmente cara ao filósofo judeu, a saber, em sua alardeada "superação dos afetos" (Nachlass/FP 1884, 26 [285], KSA 11.226), conjugada ao erro de tomar a "autoconservação" como um fim, não como efeito colateral, como de fato é (cf. FW/GC 349, KSA 3.585; Nachlass/FP 1884, 26 [313], KSA 11.233). Além disso, de maneira sinuosa Spinoza estaria entre os filósofos, que, como Kant, Hegel e Schopenhauer, seriam "homens pobres e unilaterais, [...] que o cristianismo teria corrompido" (Nachlass/FP 1884, 26 [3], KSA 11.151). Os motivos para tal "complexidade de juízos" de Nietzsche em relação a Spinoza por certo passariam, ainda uma vez, pelo que o filósofo alemão chama de "profundidade" desse último, e

18 Pouco antes disso, Nietzsche enigmaticamente afirma ter sido Spinoza um "dos mortos" com quem ele esteve no Hades, juntamente com Epicuro e Montaigne, novamente com Goethe, e Platão, e Pascal, além de Rousseau, e, como talvez seja óbvio, Schopenhauer, com os quais ainda deve discutir, "quando tiver longamente caminhado a sós" (WS/OS 408, KSA 2.534).

19 Cf. Sommer, 2012, p. 159.

20 Pois em 25 [424], primavera de 1884, Nietzsche novamente afirma ser Spinoza seu precursor, juntamente com Heráclito, Empédocles, e Goethe, ao ali enunciar a divisa "O homem é algo que tem de ser superado".

238 | Cad. Nietzsche, Guarulhos/Porto Seguro, v.42, n.1, p. 231-251, janeiro/abril, 2021. 
profundidade mesmo quanto à abrangência de sua ação de ocultação (cf. Nachlass/FP 1885, 36 [32], KSA 11.563), comparativamente a Descartes, e ainda uma vez: a profundidade com que se está a ser hipócrita, poder-se-ia dizer.

Tais profundidade e ocultação não impede a existência de temas spinozanos que Nietzsche entre invejou e almejou transfigurar, como o seu Deus sive natura, mundo sem Deus justamente por ser Deus, mundo de necessidades sem liberdade, nem transcendência, do amor intellectualis Dei, resposta prática à historicidade que Nietzsche intentaria secularizar, para daí fazer emanar o seu amor fati. $^{21}$ Pois quanto a essa construção teórica, se tantos, à época de Spinoza como depois, viram-na como escândalo e anátema, Nietzsche já a vê como um anseio disfarçado, "sempre o antigo modo religioso de pensar e desejar" (Nachlass/FP 1885, 36 [15], KSA 11.556). Spinoza, fazendo-se valer do "mais elevado e estranho pedantismo de um lógico, acreditou divinizar seu impulso de tudo conhecer absolutamente" (Nachlass/FP 1886-1887, 7 [4]; KSA 12.262-263; itálico nosso).

Outro anseio religioso do autor da Ética, coadunado ao primeiro, isto é, a enxergar Deus no mundo, estaria em sua busca pela quietude. Podemos voltar um pouco na cronologia de Nietzsche sobre Spinoza, para o espólio de 1881, e ver que este, para aquele, seria um filósofo que, muito embora tivesse tematizado os afetos como as constantes flutuações de nossa potência para mais ou para menos, e ainda embora tivesse trazido os afetos para caracterizar e de certo modo mensurar nossa "potência de pensar", ${ }^{22}$ teria fantasiado a respeito da razão - e fantasiado justamente por propor, no seio dela, afetos em união e em ausência de luta (cf. Nachlass/FP 1881, 11 [132]; KSA 9.490). E se depreendeu que o conhecimento seria o afeto mais poderoso, para Nietzsche ele assim o seria, se o fosse, como ele dirá, numa estrutura

21 Sommer, 2012, p. 169.

22 B. Espinosa, 1983, p. 182-183 (III 11 e esc.)

Cad. Nietzsche, Guarulhos/Porto Seguro, v.42, n.1, p. 231-251, janeiro/abril, 2021.| 239 
Krieger, S.

mortificada, ${ }^{23}$ própria, aliás, de quem tem a autoconservação como fim último (cf. Nachlass/FP 1884, 26 [313]; KSA 11.233).

E é justamente sobre o modo como Spinoza concebe o conhecimento que versa o aforismo em que o autor do Zaratustra mais detidamente o aborda. No aforismo 333 d'A gaia ciência, "O que significa conhecer", ao enunciado de Spinoza "Non ridere, non lugere, neque detestari, sed intelligere", ${ }^{24}$ Nietzsche contrapõe o que ele próprio entende por intelligere, a saber, "a forma pela qual justamente aquelas três coisas tornam-se de uma vez sensíveis para nós", "resultado dos diferentes e contraditórios impulsos de querer, zombar e maldizer" (FW/GC 333, KSA 3.558), e isto significa que os impulsos vão até o intelligere e propriamente são o intelligere. Justamente, na sequência de uma explanação sobre como o embate entre unilateralidades - entre diferentes impulsos - é contemporizado por justiças e contratos, tem-se dois modos de conceber o intelligere: o primeiro deles é o modo antigo, de "até agora", a versar sobre como o conhecer nos chega à consciência, a saber, "apenas nas últimas cenas de conciliação e ajuste de contas de um longo processo" (FW/GC 333, KSA 3.559; trad. modificada); o segundo modo é o do "só agora": "só agora começa a raiar para nós a verdade de que a atividade de nosso espírito ocorre em sua maior parte de maneira inconsciente e não sentida por nós" (FW/GC 333, KSA 3.559; trad. modificada; itálico nosso). Se o conhecer, assim, resulta de uma luta entre impulsos, e se esta não chega à consciência - apenas suas "últimas cenas de conciliação" (FW/GC § 333, KSA 3.559) -, não obstante os impulsos entre si se fazem sentir, exigir, resistir e dominar, como dominados são os impulsos fracos ou exauridos. E se os pensamentos que nos chegam à consciência trazem consigo o ônus

23 A ideia mesma de mortificação é expressa por Nietzsche, pois no inteiro enunciado sobre Spinoza em 11 [132], primavera-outono de 1881 KSA 9.490 se lê: "Um erro fundamental está na crença na união e na ausência de luta - isso seria justamente a morte!".

24 "[...] tive todo o cuidado em não ridicularizar as ações dos homens, não as lamentar, não as detestar, mas adquirir delas verdadeiro conhecimento". Cf. B. Espinosa, 1983, p. 306.

240 | Cad. Nietzsche, Guarulhos/Porto Seguro, v.42, n.1, p. 231-251, janeiro/abril, 2021. 
da luta e da exaustão, tanto mais luta e exaustão haverá quanto mais se exercitar o pensamento - e a esse respeito, Nietzsche hipotetiza: "a violenta e súbita exaustão que atinge todos os pensadores talvez tenha aí a sua origem" (FW/GC 333, KSA 3.559; trad. modificada).

De duas maneiras os filósofos seriam afetados pela dinâmica perversa a envolver o intelligere: a primeira delas, por exercitar sobremaneira um processo que, instaurando-se de maneira conflituosa desde suas camadas mais profundas, exige e exaure; a segunda, por admitir desse inteiro processo apenas a parte conciliatória, que é também a parte suave e menos vigorosa - afinal, mesmo as paixões eles julgam poder apartar de si mesmos e dominar. Podese dizer, em suma, que são enganados pela natureza do conhecer, cujo processo, bem mais profundo e visceral do que entendem ser, justamente os tortura e exaure -, justo enquanto imaginam a tudo conhecer absolutamente, e nisso Spinoza, o sábio por excelência, traveste o que o leva a buscar conhecer em algo divino (cf. Nachlass/ FP 1886-1887, 7 [4], KSA 12.262-263).

Sim, entre esses filósofos a esse ponto exauridos, Spinoza seria o filósofo da má saúde, o representante por excelência dos filósofos cujo filosofar foi uma espécie de vampirismo (cf. FW/GC 372, KSA 3.624): “em tais figuras, mesmo em Spinoza, não sentem vocês algo profundamente inquietante e enigmático? Não veem o espetáculo que ali se desenrola, o constante empalidecimento - a dessensualização interpretada de forma cada vez mais idealista?" (FW/GC 372, KSA 3.624). E não por acaso, entre os grandes filósofos Spinoza foi aquele que mais expressamente ansiou pela perfeita quietude interior. Tanto que sua principal obra, a Ética, se toda ela é uma aspiração a conduzir o homem à liberdade, esta já não se distingue da beatitude, ${ }^{25}$ que por sua vez já não se distingue do "amor intelectual a Deus". Mas é bem desse anseio e dessa afetação espinosana que Nietzsche desconfia. Em Para além de bem e mal ele fala da Ética como "um

25 Cf. B. Espinosa, 1983a. (V, Pref.), p. 279.

Cad. Nietzsche, Guarulhos/Porto Seguro, v.42, n.1, p. 231-251, janeiro/abril, 2021.| 241 
Krieger, S.

hocuspocus em forma matemática, com que Espinosa como que [...] encouraçou de bronze e mascarou sua filosofia [...] essa mascarada de um eremita enfermo" (JGB/BM 5, KSA 5.19). Um anseio que se faz afetação, mascarados, pois sim. Não teria sido esse anseio profunda e hipocritamente ocultado?

Ao falar em sua beatitude, do "amor ao seu saber" (JGB/BM 5, KSA 5.19), não se trata de incorrer num erro linguístico, como no caso de Descartes, e sim, indo mais fundo, de narrar apenas metade da história, ou melhor, de rastrear-se apenas até metade do caminho, de viver sua filosofia dando as costas a ela. É verdade que o exercício, da parte de Spinoza, de olhar para o mundo foi, ao que tudo indica, para Nietzsche, bem logrado: se Schopenhauer foi dos que falaram de seu "gênio" com mais vivacidade, "gênios", como Spinoza - ao lado de Platão e Goethe - seriam propriamente homens em que o espírito (Geist, como conjunto das capacidades intelectivas) pôde aparecer apenas frouxamente ligado ao caráter e ao temperamento, lançando assim um olhar puro, purificador, "para o mundo como para um deus e amar esse deus" (M/A 497, KSA 3.292) - sim, de fato Nietzsche pode ter continuado a admirar esse olhar puro e purificador para o mundo, e ter desejado incorporar a ausência de teleologia, a exclusão da vontade livre, secularizar o amor intellectualis Dei, pelo que nele há de necessidade e imanência, de fatum - por mais que desprezasse as pretensões de um amor a um deus, tanto mais sendo tal amor puramente racional, em vez de visceral ou de pulsional. ${ }^{26}$ E por mais, enfim, que viesse a acusar no Crepúsculo dos ídolos, "a teia de aranha conceitual tecida por um eremita, o amor intellectualis dei à maneira de Spinoza" (GD/CI Incursões 23, KSA 6.126).

Críticas à parte, intenções ocultas igualmente à parte, esplêndido conhecedor do mundo, por desvencilhar suas capacidades intelectivas de caráter e temperamento (M/A 497, KSA 3.292), uma chave para compreender a grande ocultação de Spinoza estaria, e indelével,

26 Sommer, 2012, p. 169-170.

242 | Cad. Nietzsche, Guarulhos/Porto Seguro, v.42, n.1, p. 231-251, janeiro/abril, 2021. 
em texto do período da "lua de mel" de Nietzsche com Spinoza: o filósofo judeu - juntamente com Platão, Pascal, Rousseau e Goethe, ali contrapostos a "dois alemães" da não vivência de si, que são Kant e Schopenhauer - teria sido daqueles cujos pensamentos "constituem uma apaixonada história de alma", havendo ali "romance, crises, catástrofes e horas supremas a perceber", enfim, "uma involuntária biografia de uma alma" (M/A 481, KSA 3.285-286).

Ora, mas por que motivo um filósofo cujos pensamentos, assim, efetivamente trazem a história de sua alma, sua biografia, ao mesmo tempo, como aqui propomos, não teria ido até o fundo dessa história? Por que tal biografia seria involuntária? É verdade que pôde contemplar "o mundo, sob a forma de uma prática e uma pré-escola do enxergar” (M/A § 497, KSA 3.292), razão pela qual Nietzsche teria querido valer-se de tal visão. Mas por que motivo, se ele pôde, afinal, biografar-se de certa maneira, não pôde se contemplar de modo mais acabado, mesmo e também voluntário? Por uma busca de neutralidade e imperturbabilidade, teria imaginado se contemplar como quem contempla o mundo, dele apartado, sendo puramente racional também para consigo mesmo? Da (pretensa) durabilidade da coisa teria imaginado a durabilidade da afecção (Affektion) com que a percebe, como Nietzsche observa na paráfrase a Kuno Fischer? (cf. Nachlass/FP 1886, 7 [4], KSA 12.262-263). O deus sive natura, admirado por Nietzsche, não teria sido, em Spinoza, uma mera ansiedade (Sehnsucht)? (cf. Nachlass/FP 1885, 36 [15], KSA 11.556)

Spinoza teria assim ocultado o ímpeto de sua busca, pretendendo ficar apenas com o mascaramento de seu resultado, vivendo a sua filosofia "pelas costas". A dar conta dessa configuração, da ocultação pela qual em certa medida se abortou o que era intenso e profundo, propomos uma interceptação inconsciente a decidir os rumos da filosofia de Spinoza - e uma interferência, aliás, que tem o caráter do qual o filósofo judeu muito quereria se esquivar: um caráter cristão. 
Krieger, S.

\section{Spinoza e a grande ocultação: o meio do caminho}

Um dos principais problemas com que a filosofia de Spinoza procura se haver é o da relação entre todo e indivíduo, entre o mundo como sistema total e o ser como existência singular. $\mathrm{O}$ todo, o mundo mais uma vez será o do século XVII, da extensão indefinida, da multiplicidade de culturas, de visões de mundo, de uma cristandade ainda vigorosa, mas cindida em duas, e com o filtro religioso adicional de um filósofo nutrido pelo seu judaísmo - antes mesmo de se entender judeu, e mesmo depois de ser excomungado -, como logo será nutrido pelo cartesianismo. Quanto ao indivíduo, o espinosismo é de fato associado a uma filosofia dos indivíduos ou das "coisas singulares", em contraposição às abstrações e generalidades que justamente fazem escapar a singularidade. ${ }^{27} \mathrm{E}$ no âmbito das coisas singulares, a lei geral, o traço mais essencial, para Spinoza, é o desejo - e desejo de perseverar em seu ser: "toda coisa se esforça, tanto quanto está em si, por perseverar em seu ser", "esse esforço" sendo entendido como "sua essência". ${ }^{28,29}$

Em se tratando do desejo propriamente humano, e tanto mais no ambiente cartesiano do século XVII, à primeira vista ele pareceria se distinguir pela presença de "consciência". ${ }^{30}$ No entanto, por mais que Spinoza invoque a consciência para diferenciar desejo de apetite - "desejo se aplica geralmente aos homens quando têm

27 E é bem assim que ele se apresenta. Cf. B. Espinosa, 1983, p. 289-291, p. 295.

28 B. Espinosa, 1983a, III 6 e III 7, p. 180-181.

29 Segundo Sommer, Nietzsche estaria a ignorar completa e propositadamente que o conatus não é apenas "uma questão de preservar um estado existente de ser, mas precisamente uma questão da dinâmica de expansão de potência que Nietzsche afirma como seu próprio conceito original" [em livre tradução]. Cf. Sommer, 2012, p. 175. Alinhamo-nos a essa posição, mas sem daí inferir que as referências negativas de Nietzsche a Spinoza sejam todas uma questão de acobertamento visando a afetar uma originalidade do filósofo alemão - e ressalte-se que, ao contrário do que dá a entender o autor, as referências negativas são extensivas aos fragmentos não publicados, como aqui em seguida se verá.

30 B. Espinosa, 1983a, III 9, p. 181.

244 | Cad. Nietzsche, Guarulhos/Porto Seguro, v.42, n.1, p. 231-251, janeiro/abril, 2021. 
consciência de seu apetite"31 -, ele rejeita a consciência como critério diferenciador, uma vez que sua noção de desejo tem o estofo de todos os esforços da natureza humana, referidos pelos nomes do próprio apetite (appetitus), de vontade (voluntas) e de desejo ou ímpeto (impetus). ${ }^{32}$ Diante desse quadro, o ser individual até pareceria estar inserido, por Spinoza, numa estrutura efetivamente viva. Ocorre que seu desejo, para Nietzsche, essência de todo ser individual, estranhamente é o de se se manter onde está, o apetite sendo o de apenas persistir na existência (cf. Nachlass/FP 1881, 11 [307], KSA 9.559) ${ }^{33}$, e já referimos aqui o seu desprezo, como o de Descartes, pelas coisas que mudam (cf. Nachlass/FP 1887, 9 [160], KSA 12.430). Assim sendo, também o conhecimento para Spinoza é repouso, quietude, é descanso na contemplação da ideia de Deus. Tanto que por ser hábil contemplador do mundo, "de olhar puro, purificador", "olha para o mundo como para um deus e ama esse deus" (M/A 497, KSA 3.292), tendo passado por uma "prática e uma pré-escola do enxergar" (M/A § 497, KSA 3.292), como sem nada exigir do mundo fora e além do que esse mundo lhe dá. Obra de tão exímio contemplador é o amor intellectualis Dei, do qual Nietzsche, reservas à parte, teria em parte haurido o seu amor fati, ao modo de reação e secularização. ${ }^{34}$ Entretanto, Spinoza imaginou a si mesmo da mesma forma que habilmente contemplava o mundo, como impassível - e a si mesmo imaginou descanso na contemplação da ideia, desejo de se manter onde está. ${ }^{35}$ Imaginou-

31 B. Espinosa, 1983a, III 9 esc., p. 182.

32 B. Espinosa, 1983a, p. 182.

33 Cf. nota 29.

34 Cf. Sommer, 2012, p. 169-170.

35 Pela paráfrase de Nietzsche a Kuno Fischer se tem que, se Spinoza foi preciso ao verificar, e propor, que "em Deus falta vontade e entendimento e personalidade e fins", ele pecaria pelo "passo em falso psicológico" de se refletir nos objetos que concebe: "se há um Bem legítimo e inescapável, duradoura e destrutiva será nele a minha satisfação, como eterna será a minha alegria. [...] como se a durabilidade de uma coisa garantisse a durabilidade da afecção" (7 [4], final de 1886 - primavera de 1887, KSA 12.262-263). 
Krieger, S.

se insensível como insensível é o mundo, imaginou "guardar-se de si mesmo" como deve se guardar em relação ao mundo (cf. FW/GC 109, KSA 3.467). Tendo ou não reconhecido e entendido o conatus como aumento de potência, Nietzsche diz sobre Spinoza: ele se basta em se autoconservar (cf. Nachlass/FP 1888,14 [121], KSA 13.301).

Um bom diagnóstico dessa situação, Nietzsche o daria justamente aqui, ao fim de seu percurso intelectual, ao observar que "um estado atingido só pareceria ter de se manter se não tivesse em si uma capacidade, justamente, a de não querer se manter..." (Nachlass/ FP 1888, 14 [121], KSA 13.301), entendendo que "o enunciado, por Spinoza, da autoconservação na verdade teria de estabelecer a alteração de uma posição" (Nachlass/FP 1888, 14 [121], KSA 13.301). No século XVII de pleno vigor da física mecanicista, situado entre as famigeradas "qualidades ocultas" e "espécies intencionais" da Escolástica e a lei da gravidade de Newton, não admira que Spinoza, ainda que sem o perceber, tendesse aos momentos estáticos, e os pretendesse para si, sob a égide do mecanicismo que, aliás, está plenamente afinado ao seu método geométrico. Nietzsche parece ter ciência disso ao arrazoar, invocando o vivente:

A afirmação de Spinoza sobre a autoconservação na verdade teria de dar um basta na mudança. Mas ela é falsa, o contrário é verdadeiro. Com a máxima nitidez se mostra em todo o vivente, que ele tudo faz não para se manter, mas para se tornar mais... (Nachlass/FP 1888, 14 [121], KSA 13.301).

Trata-se de vontade de potência, factum último a que chegamos, a que se reduzem os impulsos orgânicos (cf. Nachlass/FP 1885, 40 [61], KSA 11.661), esta que Spinoza de si teria ocultado ao ocultar do intelligere o que era voracidade, e da suposta quietude o que era busca e anseio - e avidez.

A inclinação para um desejo de perseverar que se afetará como desprovido de ânimo e de vontade, por mais que inclua e mascare uma coisa e outra, remeteria ainda para além do quadro de uma 
metafísica que Nietzsche diz ser arredia a um "ser para querer ser mais". O referido "para além" significa que Spinoza se deteve no meio do caminho. Bom contemplador do mundo (cf. M/A 497, KSA 3.293), tido por um deus que a tudo basta e a tudo se basta, mas e de si? Contemplar-se-ia tal e qual, a espelhar, de modo puro e simples, um si que se basta? De que modo suportaria se biografar?

Num fragmento póstumo em que sintomaticamente tematiza "o medo da potência como poder produtivo" (Nachlass/FP 1883, 7 [108], KSA 10.279), Nietzsche indica o "meio-do-caminho" em que Spinoza se deteve, como assinala o passo que, se o tivesse dado, não faria dele o filósofo exaurido que se tornou. No referido fragmento, associa a "fusão com a divindade", no caso de Spinoza, à "avidez [Gier] pela mais elevada imperturbabilidade". Essa avidez, que Spinoza fez ocultar, em vez de se valer como tal, como "potência de força" (Macht als produktive Gewalt), quer se refugiar em seu antípoda, a quietude. De modo que, em vez de ser propriamente busca de exercer sua potência, ela seria "consequência da mais aturdida pusilanimidade" (Nachlass/FP 1883, 7 [108], KSA 10.279). Tem-se aí, assim, na reação inconsciente e ocultada da parte de Spinoza, "o medo da potência como poder produtivo" a assumir ares da histeria própria aos santos da Igreja, ou do próprio anseio pela imperturbabilidade (Nachlass/FP 1883, 7 [108], KSA 10.279). Biografou-se involuntariamente: os afetos que o animavam, procurou destruí-los por análise e vivissecção (cf. JGB/BM 198, KSA 5.118) - acabou consumido por eles.

\section{Considerações finais}

Sim, Spinoza pode ter sido sublime (cf. FW/GC 333, KSA 3.558-559), pode ter sido precursor, gênio contemplador do mundo (cf. M/A § 497, KSA 3.293), mesmo ter dado motivos para Nietzsche sentir-se do mesmo sangue (cf. Nachlass/FP 1881, 12 [52], KSA 9.585), querer se filiar a ele (cf. carta a Franz Overbeck, 30 jul. 1881), 
Krieger, S.

querer chamar de seu, de amor fati, o amor intellectualis Dei, sem que o amor seja intelectual ou dirigido a um deus. Mas foi, talvez mais do que tudo, pusilânime. Por se deter no meio do caminho, e porque seria incapaz biografar-se voluntariamente (cf. M/A 497, KSA 3.293), de experimentar, em filosofia, os afetos que tematizava, Nietzsche não o poupa do que seria uma galeria dos hipócritas em filosofia. Sua hipocrisia estaria na "superação dos afetos" (Nachlass/FP 1884, 26 [285], KSA 11.226), que ele imaginou vivisseccionar, como se não houvesse ali um anseio por superação, e como se esse anseio não fosse ele próprio um afeto, não analisado nem vivisseccionado. Esse não reconhecimento é tão mais grave se se considerar que os afetos - afetos à maneira spinozana, não nietzschiana ${ }^{36}$-, além de tematizados, estiveram no centro de seu filosofar, a fim de que com eles fosse pensada a singularidade no universal. Para Nietzsche, seu esforço em pensar a singularidade mediante afetos, apetites e desejos pode revelar, mais do que tudo, um vivo interesse em se subtrair ao que haveria de insipidez num mecanicismo, à sua época tão promissor. Em não imaginar o mundo como um ser vivo, ou provido de teleologia (cf. FW/GC 109, KSA 3.467). Ocorre que, sem se fazer imune ao invasivo ascetismo cristão, mesmo que judeu, Spinoza pensou poder refugiar-se da ação virulenta dos próprios afetos que trouxe à baila. Imaginou poder ficar restrito à ordem do entendimento, entendimento sem afetos, fantasiou o intelligere sem a heterogeneidade que o constituía, e entenda-se, sem a ordem do corpo (cf. FW/GC 333, KSA 3.558-559). Para o autor d'A gaia ciência, a ordem do corpo, dos apetites e desejos - dos impulsos em luta permanente - cobrou seu preço, e fez de Spinoza não o mais

\footnotetext{
36 Se os afetos para Spinoza são paixões, em alusão a Descartes, autor de As paixões da alma, razão pela qual admitem uma dimensão reativa, para Nietzsche os afetos associam-se às denominações "instintos" e "impulsos", dizendo respeito a, axiologicamente, modos de atração e de repulsa que regulam as condições de vida de uma configuração pulsional. Sempre ativos, "propositivos", os afetos em Nietzsche são também sintomas de formação do material de memória, e, sendo assim, mais profundos do que as paixões (cf. 25 [514], primavera de 1884, KSA 11.148).
}

248 | Cad. Nietzsche, Guarulhos/Porto Seguro, v.42, n.1, p. 231-251, janeiro/abril, 2021. 
divino, mas o símbolo do filósofo exaurido e exangue. De quem muito compreendeu, de quem muito contemplou, sendo a contemplação algo da ordem dos afetos, muito foi exigido (cf. FW/GC 333, KSA 3.558-559). E Spinoza imaginou contemplar-se da mesma forma que contemplava o mundo, sem entender o quanto estava sendo exigido, achando que o pudesse mascarar. Fez-se um filósofo que agiu como vários outros na arte de esquivar-se - do vivo, do pathos, Outro da filosofia que leva a filosofar, da pedra do inconsciente. Nisso, pode-se dizer, Nietzsche o põe sob a régua com que confronta a tradição. Um filósofo que entre intentou e simulou embrenhar-se no pathos dos afetos, porém não foi em vão filho de seu tempo, filho de seu tipo: no meio do caminho tinha uma pedra: "o que é amor; o que é deus, se lhe falta qualquer gota de sangue?" (FW/GC 372, KSA 3.624).

\title{
The Great (and admired) Hidden: Nietzsche on Spinoza
}

\begin{abstract}
Beyond the triangulation Nietzsche-Kuno FischerSpinoza, the purpose of the article is to investigate the peculiarities of the relation between Nietzsche and Spinoza, stemming not from the biunivocal relationship restricted to Nietzsche and Spinoza, but from the references shared with other philosophers and thinkers mentioned by the German philosopher. Thenceforth, we intend to emphasize traits of a relationship based on admiration for the "deep hidden", but also on critics related to spheres that this very hidden disguised and that after all consumed him.
\end{abstract}

Keywords: Spinoza, knowledge, lived experience, affections, will to power. 
Krieger, S.

\section{Referências}

BROBJER, T. Nietzsche's Philosophical Context. An Intellectual Biography. Urbana / Chicago, 2008.

COSTA, G. B. O mais sublime dos venenos: Spinoza e Nietzsche entre o "meio cheio" e o "meio vazio". In: Revista Trágica: estudos de filosofia da imanência, Rio de Janeiro, v.10 n 2, 2017, p. 9-18.

DENAT, C. \& WOTLING, P. Dictionnaire Nietzsche. Reims: Ellipses, 2013.

ESPINOSA, B. Ética (col. “Os pensadores”). Trad. Joaquim Ferreira Gomes. São Paulo: Abril Cultural, 1983.

. Tratado teológico-político. Trad. Diogo Pires Aurélio. São Paulo: Martins Fontes, 2003.

KRIEGER, S. "Como assimilar seu antípoda? Nietzsche e a superação do legado kantiano". In: Estudos Nietzsche, v. 10, n. 2, jul./dez. 2019, p. 30-49.

. "Um olhar de Nietzsche ao século XVII: Os subterrâneos da revolução cartesiana”. In: Cadernos Nietzsche, vol. 39, n. 3, set. - dez. 2018, p. 223-245.

MARTINS, A. "Nietzsche, Espinosa, o acaso e os afetos. Encontros entre o trágico e o conhecimento intuitivo". In: $O$ que nos faz pensar, n. 14, agosto de 2000, p. 183-198.

MARTON, S. "Nietzsche, leitor de Espinosa". In: Nietzsche, seus leitores, suas leituras. São Paulo: Barcarolla, 2010.

MARTON, S. \& GEN - Grupo de Estudos Nietzsche. Dicionário Nietzsche. São Paulo: GEN/Edições Loyola, 2016.

NIETZSCHE, F. A gaia ciência. Trad. Paulo César de Souza. São Paulo: Companhia das Letras, 2011.

.Aurora. Trad. Paulo César de Souza. São Paulo: Companhia das Letras, 2008.

. Além do bem e do mal. Trad. Saulo Krieger. São Paulo: Edipro, 2019.

. Crepúsculo dos ídolos. Trad. Saulo Krieger. São Paulo: Edipro, 2020.

250 | Cad. Nietzsche, Guarulhos/Porto Seguro, v.42, n.1, p. 231-251, janeiro/abril, 2021. 
. Genealogia da moral. Trad. Paulo César de Souza. São Paulo: Companhia das Letras, 2010.

. Humano, demasiado humano I. Trad. Paulo César de Souza. São Paulo: Companhia das Letras, 2012.

. Humano, demasiado humano II. Trad. Paulo César de Souza. São Paulo: Companhia das Letras, 2011.

. Sämtliche Werke. Kritische Studienausagabe in 15 Bänden. Berlin / New York: Walter de Gruyter, 1999.

. Sämtliche Briefe. Kritische Studienausgabe. Berlin / New York: Walter de Gruyter, 1999.

SCANDELLA, M. "Did Nietzsche Read Spinoza? Some Preliminary Notes on the Nietzsche-Spinoza Problema, Kuno Fischer and Other Sources." In: NietzscheStudien, n. 41, 2012, p. 308-332.

SOMMER, A. U. "Nietzsche's Readings on Spinoza. A Contextualist Study, Particularly on the Reception of Kuno Fischer." In: Journal of Nietzsche Studies, vol. 43, n. 2, 2012.

VIESENTEINER, J. "O conceito de vivência (Erlebnis) em Nietzsche. Gênese, significado e recepção". Kriterion, n. 127, junho 2013, p. 141-155.

YASUKATA, T. Lessing's Philosophy of Religion and the German Enlightenment. Oxford: Oxford University Press, 2002. 